Research Paper

\title{
Erythropoietin Alleviates Burn-induced Muscle Wasting
}

\author{
Sheng-Hua $\mathrm{Wu}^{1,2,3,4}$, I-Cheng Lu' ${ }^{1,2,3}$, Ming-Hong Tai ${ }^{5,6}$, Chee-Yin Chai ${ }^{7,8,9}$, Aij-Lie Kwan ${ }^{8,10}$, Shu-Hung \\ Huang $10,11,12 \bowtie$
}

1. Department of Anesthesiology, Kaohsiung Medical University Hospital, Kaohsiung Medical University, Kaohsiung, Taiwan.

2. Department of Anesthesiology, School of Medicine, College of Medicine, Kaohsiung Medical University, Kaohsiung, Taiwan.

3. Department of Anesthesiology, Kaohsiung Municipal Hsiao-Kang Hospital, Kaohsiung Medical University, Kaohsiung, Taiwan.

4. Department of Anesthesiology, Kaohsiung Municipal Ta-Tung Hospital, Kaohsiung, Taiwan.

5. Center for Neuroscience, National Sun Yat-Sen University, Kaohsiung, Taiwan.

6. Department of Biotechnology, Southern Taiwan University of Science and Technology, Tainan, Taiwan.

7. Departments of Pathology, College of Medicine, Kaohsiung Medical University, Kaohsiung, Taiwan.

8. Faculty of Medicine, College of Medicine, Kaohsiung Medical University, Kaohsiung, Taiwan.

9. Institute of Biomedical Sciences, National Sun Yat-Sen University, Kaohsiung, Taiwan.

10. Department of Surgery, School of Medicine, College of Medicine, Kaohsiung Medical University, Kaohsiung, Taiwan.

11. Division of Plastic Surgery, Department of Surgery, Kaohsiung Medical University Hospital, Kaohsiung, Taiwan.

12. Regeneration Medicine and Cell Therapy Research Center, Kaohsiung Medical University, Kaohsiung 807, Taiwan.

$\triangle$ Corresponding author: Shu-Hung Huang, Tel: 886-7-3121101*7676; E-mail: huangsh63@gmail.com

(C) The author(s). This is an open access article distributed under the terms of the Creative Commons Attribution License (https://creativecommons.org/licenses/by/4.0/). See http://ivyspring.com/terms for full terms and conditions.

Received: 2019.07.20; Accepted: 2019.11.05; Published: 2020.01.01

\begin{abstract}
Background: Burn injury induces long-term skeletal muscle pathology. We hypothesized EPO could attenuate burn-induced muscle fiber atrophy.

Methods: Rats were allocated into four groups: a sham burn group, an untreated burn group subjected to third degree hind paw burn, and two burn groups treated with weekly or daily EPO for four weeks. Gastrocnemius muscle was analyzed at four weeks post-burn.

Results: EPO attenuated the reduction of mean myofiber cross-sectional area post-burn and the level of the protective effect was no significant difference between two EPO-treated groups $(p=0.784)$. Furthermore, EPO decreased the expression of atrophy-related ubiquitin ligase, atrogin-1, which was up-regulated in response to burn. Compared to untreated burn rats, those receiving weekly or daily EPO groups had less cell apoptosis by TUNEL assay. EPO decreased the expression of cleaved caspase 3 (key factor in the caspase-dependent pathway) and apoptosis-inducing factor (implicated in the caspase-independent pathway) after burn. Furthermore, EPO alleviated connective tissue overproduction following burn via transforming growth factor beta 1-Smad2/3 pathway. Daily EPO group caused significant erythrocytosis compared with untreated burn group but not weekly EPO group.

Conclusion: EPO therapy attenuated skeletal muscle apoptosis and fibrosis at four weeks post-burn. Weekly EPO may be a safe and effective option in muscle wasting post-burn.
\end{abstract}

Key words: Erythropoietin, Muscle fiber atrophy, Burn injury, Apoptosis Inducing Factor, Transforming Growth Factor beta1

\section{Introduction}

Muscle fiber atrophy is a hallmark of several critical disorders, including burn injury [1-4]. A decline of skeletal muscle impairs patient recovery, including prolonged mechanical ventilation use, poor wound healing, and increased risk of infection [5-7]. Burn injury is considered the most devastating injury that may cause long-term muscle wasting and a decrease in muscle strength over several months [8-10]. Persistent muscle atrophy following burn impedes full recovery $[9,11]$. The underlying cellular mechanisms leading to burn-induced muscle wasting remain elusive and effective therapeutic options are in demand for these patients. A consequence of central nerve system denervation following burn injury 
subsequently causes muscle wasting. A burn mice study indicated that upregulation of cytokines and chemokines post-burn resulted in microglia activation, motor neuron degeneration and muscle loss [12]. In addition, several possible pathogeneses within skeletal muscle contribute to burn-induced muscle wasting. Recent studies showed the level of muscle pro-catabolic or muscle-specific secretory factor was increased under burn serum stimulation [13, 14]. Persist hypermetabolic state in response to burninduced proinflammatory cascades and catabolic hormones ultimately caused skeletal muscle breakdown $[8,15,16]$. The activation of skeletal muscle cell autophagy also played a role in skeletal muscle wasting following burn [17]. A possible bone secreted factor, TGF- $\beta$, also involved in burn-induced muscle cachexia by increasing oxidative damage to muscle [18].

Furthermore, previous studies have proposed skeletal muscle cell apoptosis was increased following burn and involved in classical caspase-dependent pathways [19-23]. As Yasuhara et al reported increased apoptosis and caspase- 3 activity in skeletal muscle within a few hours after burn in a rat model [20]. Other burn model showed maximal apoptosis occurred on four days after injury and caspase- $3,-8$ and -9 activity increased in tibialis anterior muscle [22]. Moreover, the role of caspase-independent mediated apoptosis has rarely been discussed in burn injury models. The release of apoptosis-inducing factor (AIF) might associate with an increased skeletal muscle apoptotic potential, and result in muscle atrophy [24]. Muscle biopsies of rat and human suggested age-related muscle loss might be involved in the activation of $\operatorname{AIF}[25,26]$. Another process impairs muscle regeneration associated with overproduction of extracellular matrix (ECM) [27]. Abnormal muscle repair and excessive ECM deposition consequently progress toward fibrosis post-acute phase of trauma, which often causes poor response to pharmaceutical therapy. Burn injury often results in hypermetabolic state and production of various inflammatory factors [7, 28-31]. Transforming growth factor beta 1 (TGF- $\beta 1$ ) is a crucial factor to regulate ECM remodeling $[32,33]$ and drives tissue to fibrosis in chronic inflammatory diseases. Inhibition of TGF- $\beta 1$ activity enhances tissue repair [34, 35]. Research of burn scars reports that TGF- $\beta 1$ acts through the Smad protein system to activate genes related to fibrosis $[36,37]$. In addition, a downstream effector of TGF- $\beta 1$, connective tissue growth factor (CTGF) was sustained increase in several fibrotic conditions [37-41] included burn scars to regulate ECM synthesis. However, scanty data investigated their pro-fibrotic role in skeletal muscle at the post-acute phase of burn and possible therapeutic agents.

Erythropoietin (EPO) is a pleiotropic hormone whose primary function is to stimulate erythropoiesis. Its target receptors are expressed in several cell types including skeletal muscle [42-49]. EPO has a tissue protective potential, including anti-inflammation, anti-apoptosis, and improving metabolic alteration [48, 50-53]. EPO reduced cells apoptosis and inhibited pro-inflammatory cytokines in sepsis-induced lung injury model [54] as well as in kidney ischemia/ reperfusion injury model [55]. Neuroprotection of EPO was supported in ameliorating PC 12 cells against oxidative stress [56]. EPO protected heart from fibrosis by suppressing TGF- $\beta 1$, collagen and pro-inflammatory cytokines expression in rat cardiac fibroblasts and in a rat model of cardiac remodeling $[57,58]$. For critical trauma patients, EPO therapy might reduce mortality and improve outcome without increasing adverse events [59-61]. However, the precise role and regulatory mechanisms of EPO in skeletal muscle remains uncertain [62]. Human muscle biopsies showed EPO induces myogenic differentiation factor expression in satellite cells, which participate in muscle regeneration following 10 weeks EPO treatment [63] and improves type I muscle fiber diameter in hemodialysis patients [64]. A diabetic mice model reported that 4 and 8 weeks EPO therapy reduced skeletal muscle insulin resistance by increasing autophagy and reducing apoptosis [65]. EPO increased erythropoietin receptor expression and induced cell proliferation in $\mathrm{C} 2 \mathrm{C} 12$ myoblasts and satellite cells [66]. In addition, exercise training and erythropoietin attenuated muscle alterations in cancer cachexia [67]. These data suggest the potential therapeutic role of EPO in muscle wasting post-burn.

In this rat study, we investigated the impact of burn on gastrocnemius muscle at four weeks post-burn and hypothesized EPO could prevent muscle wasting through anti-apoptosis and antifibrosis. We induced a burn trauma in the right hindpaw among three groups of rats, two treated with $\mathrm{EPO}$, one group treated daily and the other group treated weekly. The pharmacological effect of EPO on caspase-dependent and caspase-independent mediated cell apoptosis was investigated. In addition, the anti-fibrogenic mechanism of EPO on TGF- $\beta 1$ induced CTGF expression to regulated ECM synthesis was also investigated.

\section{Materials and Methods}

The study used 24 adult, male Sprague-Dawley rats. The procedures were approved and conduced in accordance with the guidance of the Institutional Animal Care and Use Committee at Kaohsiung 
Medical University (IACUC Approval Number: 106047). On day 0 (D0), all animals received either a third-degree burn or sham burn injury and wound care following a previous thermal model [68]. The rats were randomly allocated into four groups of six rats each: (1) a sham-control group (sham burn group) which received a sham burn and no drug treatment; (2) an untreated burn-only group (burn group); (3) a burn group treated with weekly EPO for four weeks (weekly EPO group) (5000 IU/kg i.p. at day 0, week 1 , 2, 3 [D0, W1, 2, 3]); and (4) a burn group treated daily with EPO for four weeks (daily EPO group) (3000 $\mathrm{IU} / \mathrm{kg} /$ day i.p. at day 0 to day 27 [D0-D27]).

The right hind paw of each rat topped with 100-g weight (to maintain a standardized surface contact) was placed, plantar side down, on a temperaturecontrolled metal surface for 10 seconds [68]. The metal surface was set at $25 \pm 0.5^{\circ} \mathrm{C}$ for the sham burn group. It was set at $75 \pm 0.5^{\circ} \mathrm{C}$ for the three study groups, resulting in a third-degree thermal injury. The weekly and daily EPO groups both received recombinant EPO (Epoetin, Recormon, Roche) administered intraperitoneally (i.p) immediately after the burn injury. Afterwards, two groups were treated with daily or weekly EPO as scheduled. Our preparation of EPO and the dosage we used were based on our previous study [69]. Four weeks (W4) after burn, blood samples were collected to measure red blood cell (RBC) mass by an autoanalyzer (Bayer ADVIA 2120). Then all rats were euthanized by administration of Zoletil 50 overdose and perfused with $4 \%$ paraformaldehyde. The gastrocnemius muscle of the right limb of each rat was harvested for histological analysis.

Tissue samples from the mid-belly of the gastrocnemius muscle were fixed by formalin, embedded in paraffin and cut into 4- $\mu$ m-thick sections. Serial tissue slices were mounted on glass slides, deparaffinized, and rehydrated in graded alcohol solutions. Muscle sections were stained with Hematoxylin and Eosin (H\&E) staining (Abcam, Cambridge, MA) according to the manufacturer's directions and visualized by light microscopy. The average muscle cross-sectional area of each experimental group was acquired from six stained sections of each specimen using a Nikon eclipse E600 and capture with Nikon digital sight DS-5M. Images were obtained for the morphometric analyses with image analysis software IPP6.0 (Media Cybernetics, Bethesda, USA) after observing under a microscope.

To detect apoptotic cell death, TdT dUTP nick-end labeling (TUNEL) assay was performed according to the manufacturer's directions (Millipore, ApopTag fluorescein in situ apoptosis detection kit
S7110). After incubated with 5\% normal goat serum for 1 hour, the sections were incubated with cleaved caspase 3 (1: 200; Cell Signaling, Beverly, MA) or apoptosis-inducing factor (AIF, 1: 200, Abcam, Cambridge, MA) overnight at $4^{\circ} \mathrm{C}$. Subsequently, all of them were incubated with Cy3-conjugated antimouse IgG secondary antibody (MerckMillipore, Bedford, MA) at room temperature for an additional 1 hour, rinsed 3 times with PBS for 5 minutes each, and mounted with a medium containing 4'6-diamidino2phenylinodole (DAPI) for identifying nuclei. TUNEL index was calculated as the number of TUNELpositive nuclei to the gross area of nuclei according to a previous study [25].

Muscular fibrotic changes were analyzed by immunofluorescence with fibronectin (1: 200, Novus Biologicals, Littleton, CO, USA), type I collagen (1: 200, Novus Biologicals, Littleton, CO, USA), type III collagen (1:200, Origene, Rockville, Maryland, USA) and phosphorylated Smad2/3 (1:200, Cell Signaling, Beverly, MA). The appropriate secondary antibody conjugated with goat anti-rabbit Cy3 (1:400, red, Millipore, Temecula, CA). All images were acquired using a fluorescence microscope (Leica DM 6000).

Western blotting of the tissue samples was performed as described previously [69]. The antibodies used were atrogin-1 (1: 1000; affinity biosciences, Changzhou, China), cleaved caspase 3 (1: 1000; Cell Signaling, Beverly, MA), apoptosisinducing factor (AIF) (1:1000, Abcam, Cambridge, MA), fibronectin (1:1000, Novus Biologicals, Littleton, CO, USA), type I collagen (1:1000, Novus Biologicals, Littleton, CO, USA), Type III collagen (1:1000, Origene, Rockville, Maryland, USA), transforming growth factor beta-1 (TGF- $\beta 1)$ (1:1000, Abcam, Cambridge, MA), connective tissue growth factor (CTGF) (1: 1000, Novus Biologicals, Littleton, CO, USA) and GADPH (1:2000, Sigma-Aldrich, Poole, Dorset, UK) were performed. The muscle lysates were centrifuged at $13,000 \times \mathrm{RPM}$ at $4^{\circ} \mathrm{C}$ for 30 minutes. Each protein concentration of the supernatants was measured using bovine serum albumin as the standard. The above antibody-bound proteins were detected using chemiluminescence detection regents and the total signal was quantified using Image Lab.

All values were expressed as means \pm standard error of the mean (SEM). All data were calculated according to the numerical data, as presented in the text. All statistical operations were performed using SPSS (ver.14.0, Chicago, IL, USA). A $p<0.05$ was considered statistically significant. ${ }^{*} \mathrm{p}<0.05 .{ }^{* *} \mathrm{p}<$ 0.01 . 


\section{Results}

\section{Weekly EPO did not cause significant erythrocytosis}

To investigate whether two EPO regimens lead to the obvious erythrocytosis, we checked red blood cell (RBC) count of four groups (shown in Table 1). Compared to untreated burn rats, those treated with weekly EPO did not have significantly altered RBC count $\left(7.84 \pm 0.99 \times 10^{6} / \mathrm{uL}\right.$ vs. $8.07 \pm 0.88 \times 10^{6} / \mathrm{uL}$, $\mathrm{p}=0.069$ ), while those treated daily EPO did $\left(7.84 \pm 0.99 \times 10^{6} / \mathrm{uL}\right.$ vs. $\left.10.41 \pm 0.87 \times 10^{6} / \mathrm{uL}, \mathrm{p}=0.001\right)$.

\section{EPO alleviated burn-induced muscle fiber atrophy and the expression of atrophy-related ubiquitin ligase, atrogin-1}

H\&E staining showed significant muscle fiber atrophy at four weeks post-burn in Figure 1. Both EPO-treated groups attenuated the reduction in the mean cross-sectional area of myofibers. There was no significant difference between EPO-treated groups $(p=0.784)$. Furthermore, atrogin- 1 is an important regulator of ubiquitin-mediator protein degradation in skeletal muscle. An increase expression was found in aged rats with the decline of muscle mass [70] and during muscle atrophy [71]. Our result showed that the atrophy-related ubiquitin ligase was significantly up-regulated in burn untreated group in comparison with sham groups $(p=0.032)$. Compared to the untreated burn group, both EPO-treated groups attenuated the expression of atrogin-1 (Weekly EPO, $\mathrm{p}=0.048$, Daily EPO, $\mathrm{p}=0.041$ ).

Table 1. Effect of EPO on erythrocytosis

\begin{tabular}{lllllll}
\hline & Sham burn & Burn injury & Weekly EPO & Daily EPO & $p^{\text {B-A }}$ & $p^{\text {C-B }}$ \\
\hline $\operatorname{RBC}\left(x 10^{6} / \mu \mathrm{L}\right)$ & $7.51 \pm 0.34$ & $7.84 \pm 0.99$ & $8.07 \pm 0.88$ & $10.41 \pm 0.87$ & 0.709 & 0.069
\end{tabular}

Data are presented as the mean \pm SEM. ${ }^{* *}$ : $p<0.01$.

$\mathrm{p}^{\mathrm{B}-\mathrm{A}}$ : burn-untreated versus sham-burn group,

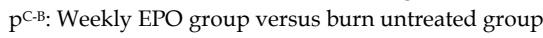

$\mathrm{p}^{\mathrm{D}-\mathrm{B}}$ : Daily EPO group versus burn untreated group.

RBC: Red blood cell.

\section{$1 \mathrm{~A}$ \\ Hematoxylin}

Sham burn

Burn untreated

Weekly EPO

Daily EPO
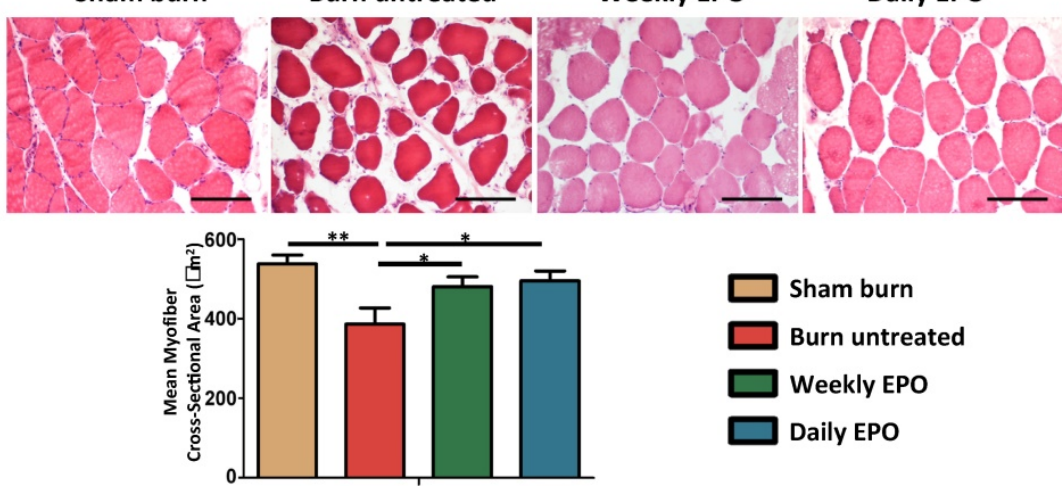

1B
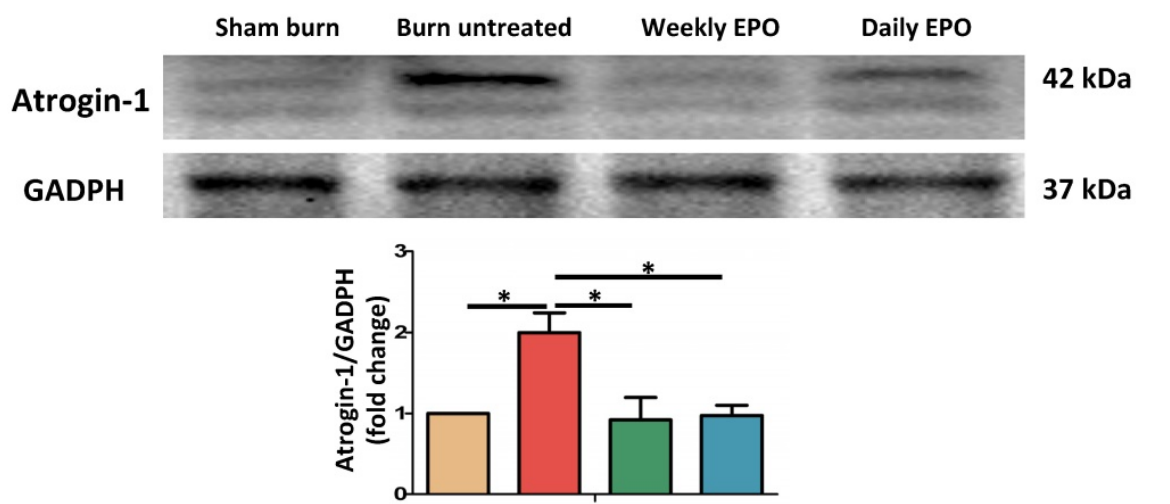

Figure 1. EPO on burn-induced muscle fiber atrophy and atrophy-related ubiquitin ligase, atrogin-1 (A) Representative H\&E staining of gastrocnemius muscle section (200x). Average myofiber cross-sectional area of 4 groups. (B) Representative western blot of atrogin-1. EPO decreased the elevation of atrogin-1 post-burn. All error bars represented the SEM. ${ }^{*} \mathrm{p}<0.05$, ${ }^{*} \mathrm{p}<0.01$. 


\section{EPO attenuated burn-induced muscle apoptosis}

In Table 2, compared to the sham burn group, the untreated burn group shows a significant increase in the number of TUNEL-positive nuclei $(p=0.008)$. Compared to the untreated burn group, both EPO-treated groups had markedly decreased cell apoptosis (Weekly EPO, p=0.040, Daily EPO, $\mathrm{p}=0.028$ ). In anti-apoptotic efficacy, weekly EPO was no inferior to daily EPO $(\mathrm{p}=0.08)$.

Table 2. TUNEL index in gastrocnemius muscle

Grouping Sham burn Burn untreated Weekly EPO Daily EPO

$\begin{array}{llll}\text { TUNEL-positive } 4.32 \pm 3.76 & 33.56 \pm 5.84 & 16.07 \pm 6.82 & 13.23 \pm 6.36\end{array}$ cell/HPF ( $x 400)$

Data was presented as the mean \pm SEM.

\section{EPO attenuates apoptosis post-burn by decreasing cleaved caspase 3}

For immunostaining localized to cleaved caspase 3 , the nuclei for DAPI and TUNEL assay are shown in Figure 2A. The untreated burn group had an increased number of TUNEL-stained cells and the expression of cleaved caspase 3 (indicated by arrowhead). Both EPO-treated groups improved the phenomenon. The ratio of TUNEL/cleaved caspase 3 positive apoptotic cells was counted. We found an attenuation of the TUNEL/cleaved caspase 3 positive apoptotic cell ratio in both EPO-treated groups. Figure 2B shows the protein expression of cleaved caspase 3 by western blot. Cleaved caspase 3 was significantly decreased in both EPO-treated groups compared to the untreated burn group. We suggest EPO could attenuate caspase 3-mediated apoptosis post-burn.

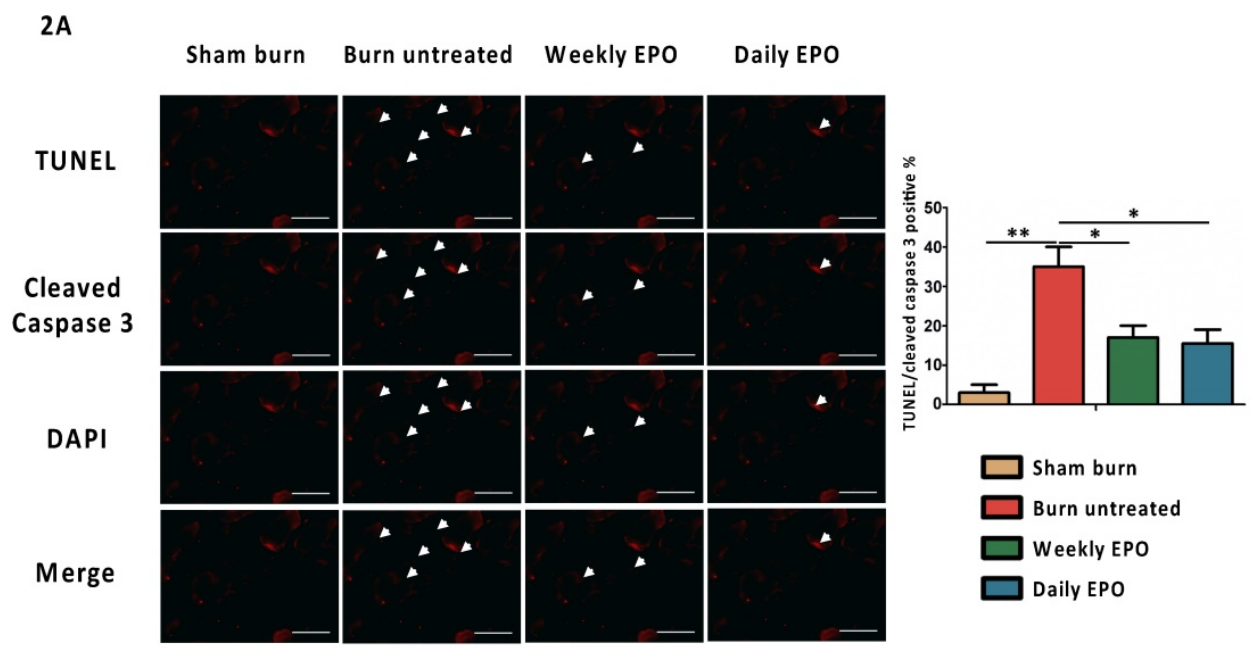

2B

Sham burn Burn untreated Weekly EPO Daily EPO

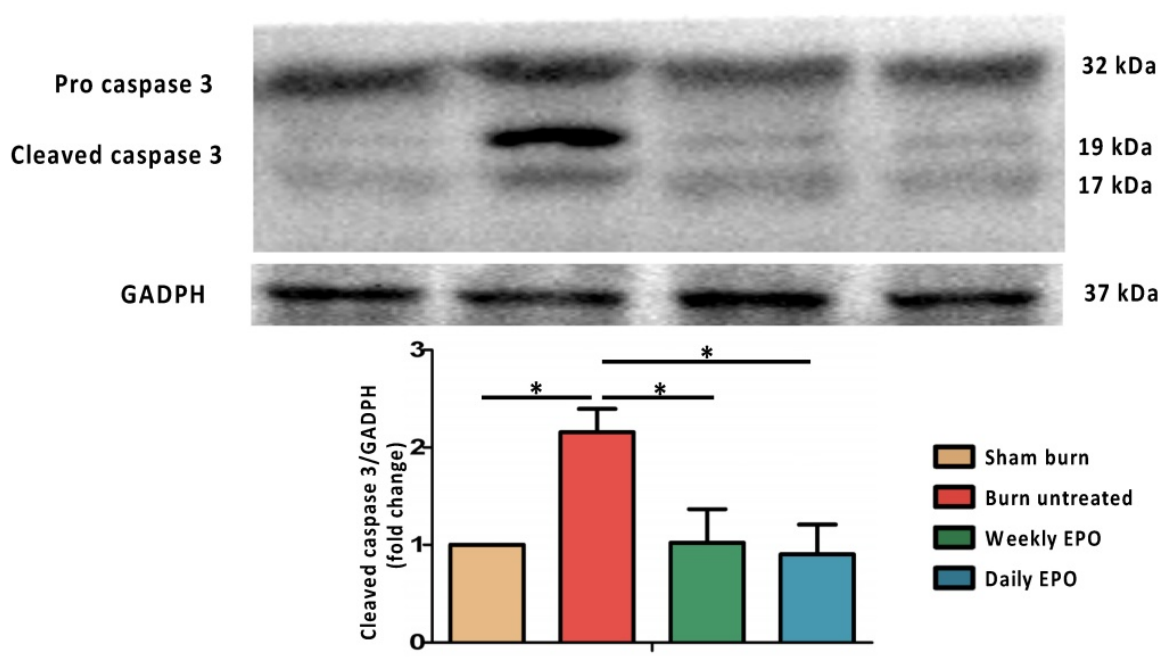

Figure 2. EPO on cleaved caspase 3 mediated apoptosis. (A) Representative TUNEL stain (green) and immunofluorescence of cleaved caspase 3 (red). DAPI (blue) was used for nuclear counterstaining. Arrowheads indicated positive-staining cells. EPO-treated groups showed less TUNEL/cleaved caspase 3 positive cells. (B) The expression of cleaved caspase 3 by western blot. EPO decreased the elevation of cleaved caspase 3 post-burn. All error bars represented the SEM. * $<<0.05$, ** $p<0.01$. Scale bar: $50 \mu \mathrm{m}$. 
3A

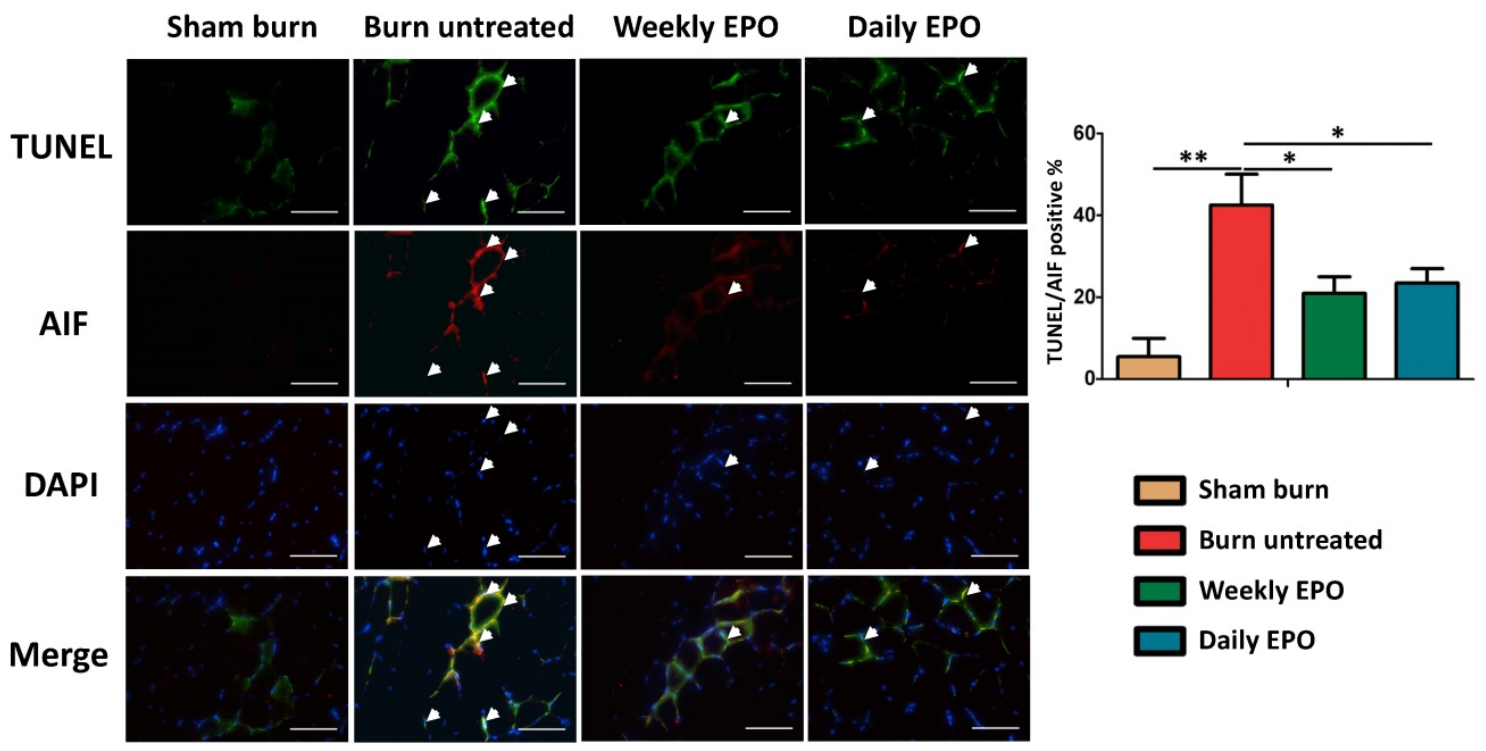

3B

\section{Sham burn Burn untreated Weekly EPO Daily EPO}

AlF

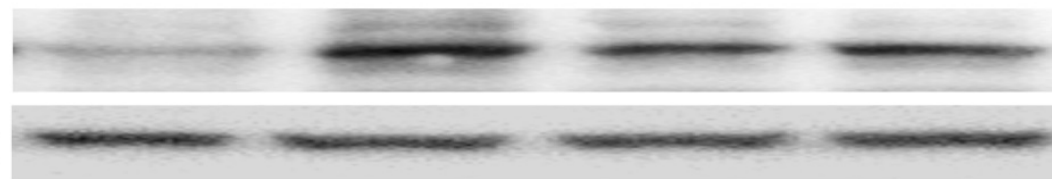

$67 \mathrm{kDa}$

GADPH

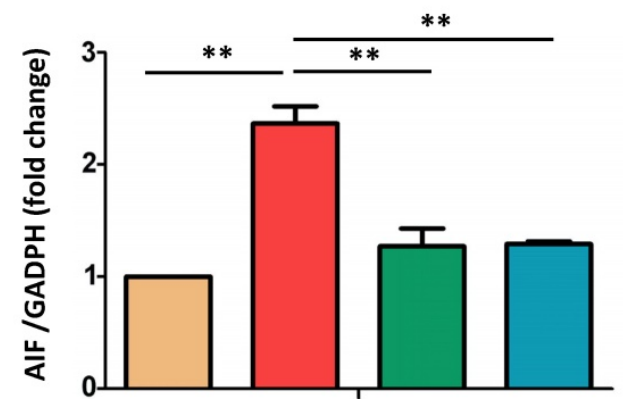

$37 \mathrm{kDa}$

Figure 3. EPO on AIF mediated apoptosis. (A) Representative TUNEL stain (green) and immunofluorescence of AIF (red). DAPI (blue) was used for nuclear counterstaining. Arrowheads indicated positive-staining cells. TUNEL/AIF-positive cells were decreased in both EPO-treated groups. (B) Representative western blot of AIF. EPO decreased the elevation of AIF post-burn. AIF: Apoptosis-inducing factor. All error bars represented the SEM. $*_{p}<0.05$, **p<0.01. Scale bar: $50 \mu \mathrm{m}$.

\section{EPO attenuated apoptosis-inducing factor mediated apoptosis post-burn}

Caspase-independent pathway, apoptosisinducing factor (AIF) might also be involved in apoptotic events post-burn. As shown in the merged image in Figure $3 \mathrm{~A}$, we found an increase in co-localized AIF with TUNEL-stained apoptotic cells (indicated by arrowheads) and EPO attenuated the phenomenon. EPO-treated groups had less TUNEL/ AIF positive apoptotic cells. Figure 3B showed the western blot of AIF. The protein expression of AIF was elevated in untreated burn rats, but not in EPO-treated rats.

\section{EPO attenuated burn-induced extracellular matrix proteins overproduction}

Figure $4 \mathrm{~A}$ shows the immunofluorescence of ECM proteins (type I collagen, type III collagen, and fibronectin). The untreated burn rats had an overexpression of ECM proteins compared with other groups. Western blot in Figure 4B also showed that EPO attenuated ECM protein production following burn. 
4A

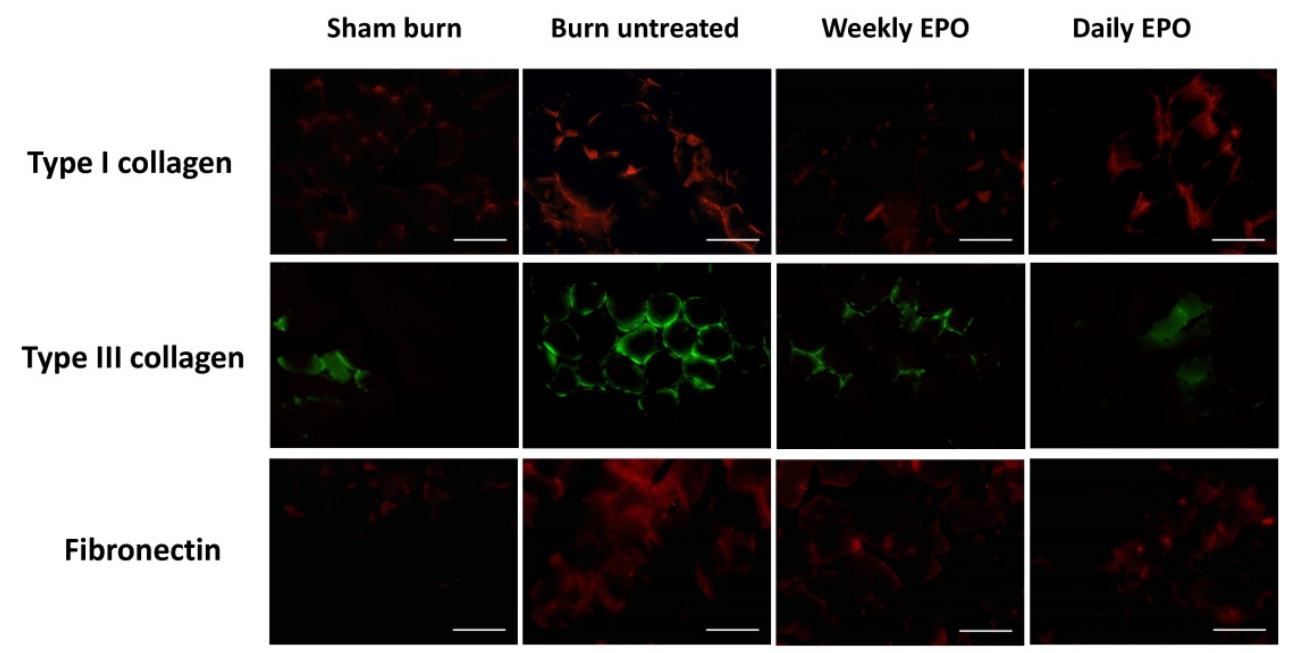

4B

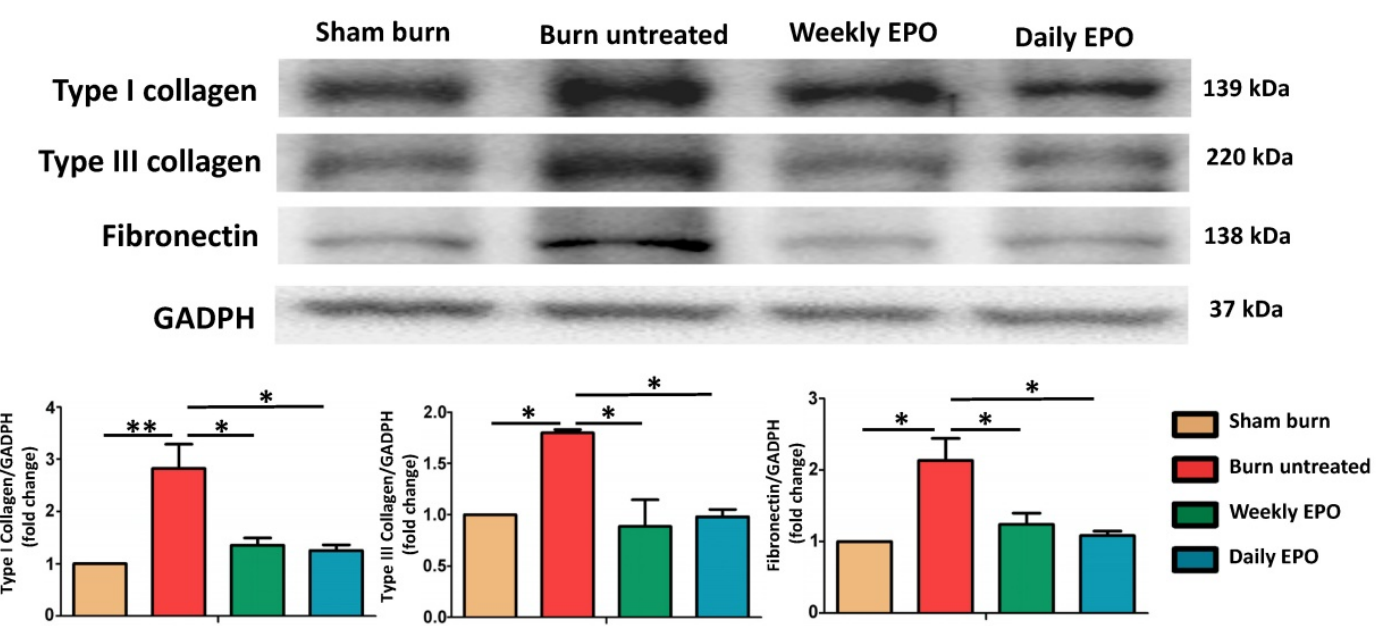

Figure 4. EPO on ECM overproduction following burn. (A) Immunofluorescence images of type I collagen, type III collagen and fibronectin. The expression of ECM proteins was significantly increased in untreated burn group but not in EPO-treated groups. (B) Western blot revealed EPO attenuated burn-induced ECM proteins elevation. ECM: extracellular matrix. All error bars represent the SEM. ${ }^{*} \mathrm{p}<0.05$. Scare bars $=100 \mu \mathrm{m}$.

\section{EPO improved burn-induced muscle fibrosis by TGF- $\beta 1 /$ Smad signaling to decrease CTGF expression}

Western blot was used to analyze the pro-fibrotic activity of TGF- $\beta 1$ and CTGF expression (Figure 5A). Compared to sham-burn group, the untreated burn rats had a 2.7-fold and 2.1-fold increase in TGF- $\beta 1$ and CTGF respectively. The EPO-treated groups attenuated their elevation post-burn. Furthermore, we found EPO decreased Smad 2/3 phosphorylation (pSmad2/3) by immunofluorescence and western blot (Figure 5B). We suggested EPO suppressed TGF- $\beta 1 /$ Smad pathway to down-regulate CTGF expression post-burn.

\section{Discussion}

Typically, critical illness including burn leads to muscle wasting for a prolonged period. In this study, we investigated gastrocnemius muscle at four weeks post-burn and the therapeutic potential of EPO in muscle wasting. We found EPO could prevent cleaved caspase- 3 and AIF mediated apoptotic cell death as well as maintain muscle fiber diameter following burn. EPO also attenuated burn-induced collagens and fibronectin deposition. The possible mechanism mediated via TGF- $\beta 1 / \mathrm{Smad} 2 / 3$ signaling to decrease the expression of CTGF. EPO therapy attenuated burn-induced skeletal muscle wasting through anti-apoptotic and anti-fibrotic effects. Weekly EPO was non-inferior efficacy to daily EPO and did not alter red blood cell count. This study may provide information not only for burn patients but also possibly for those suffering from critical disease-induced muscle wasting. 
$5 A$
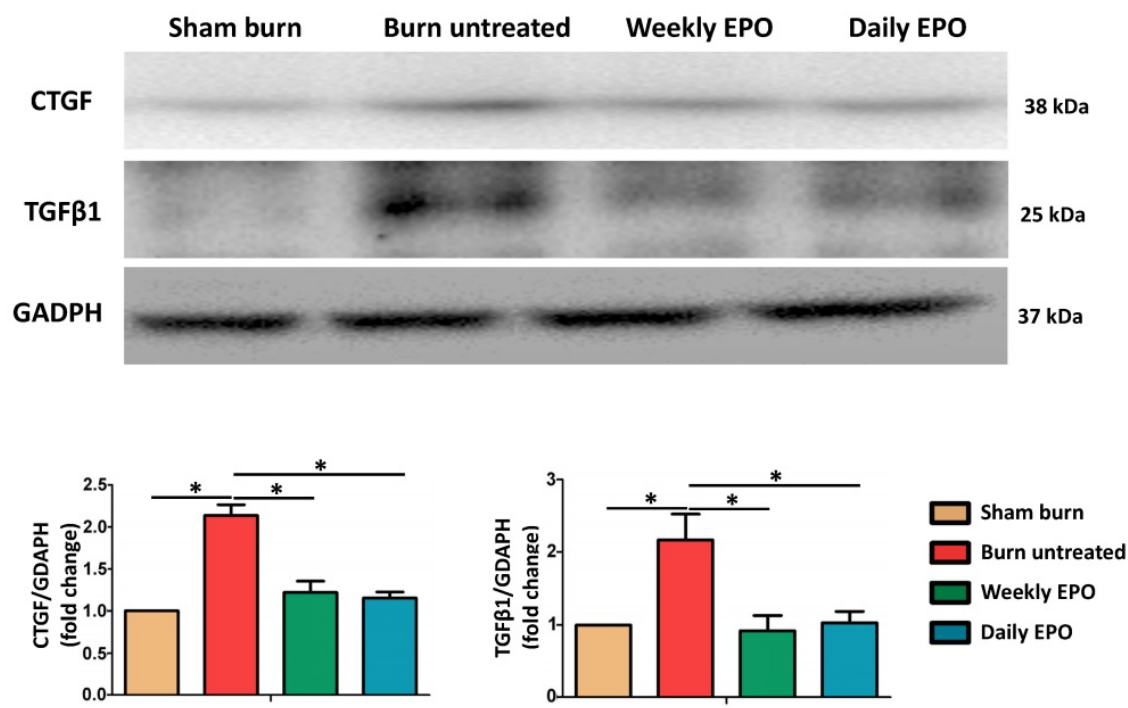

$5 B$

Sham burn

Burn untreated

Weekly EPO

Daily EPO
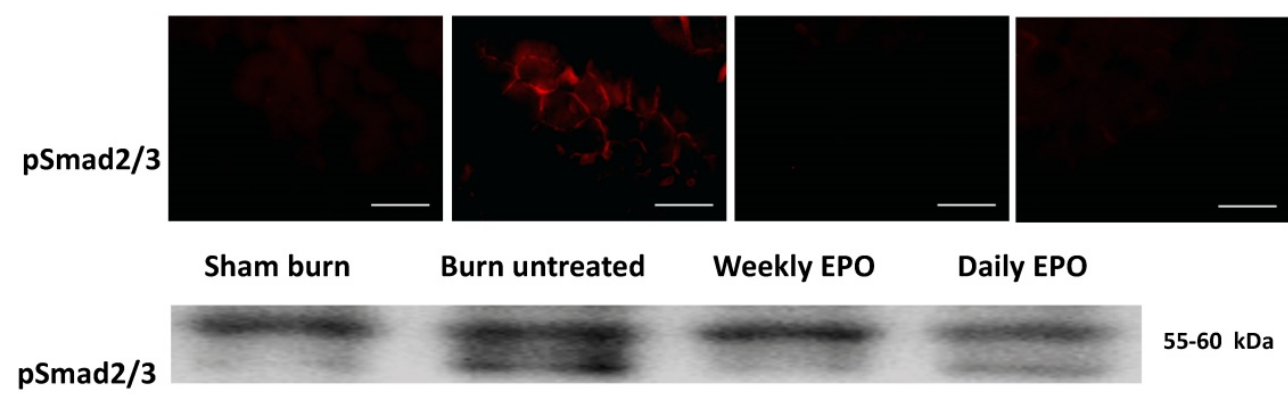

GADPH

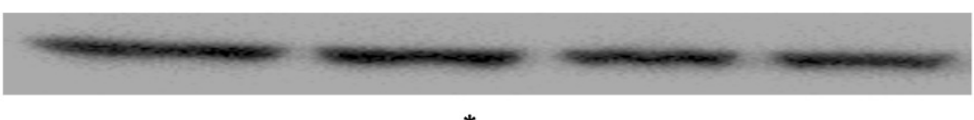

$37 \mathrm{kDa}$

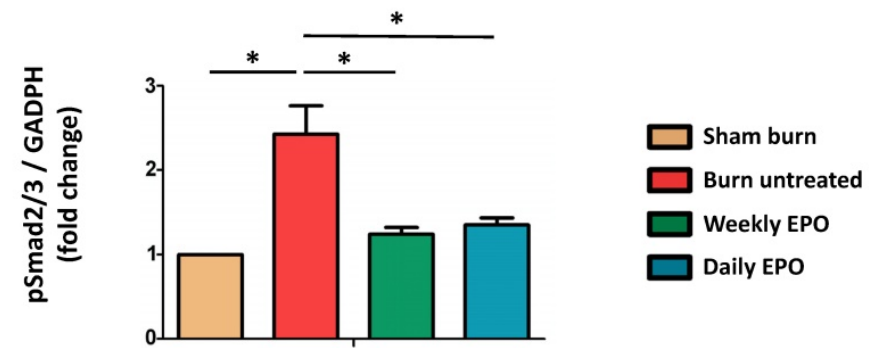

Figure 5. EPO alleviated burn-induced muscle fibrosis by suppressing TGF- $\beta 1 / \mathrm{Smad}$ pathway. (A) Representative western blot of CTGF and TGF- $\beta 1$. EPO attenuated the overexpression of CTGF and TGF- $\beta 1$ post-burn. (B) Immunofluorescence and western blot of pSmad2/3 in muscle sections. EPO attenuated the overexpression of pSmad2/3 after burn. TGF- $\beta 1$ : Transforming growth factor- $\beta 1$, CTGF: Connective tissue growth factor, pSmad2/3: phosphorylated Smad2/3. $*_{\mathrm{p}}<0.05$.

Skeletal muscle wasting following critical illness is an important clinical feature and often associated with poor outcomes $[6,8,72]$. To understand the underlying mechanisms and seek effective regimen to enhance patients' recovery are needed. Several mechanisms may contribute to burn-induced muscle wasting. Alteration of mitochondrial function [72-74] and activation of inflammatory cascades $[1,75]$ within skeletal muscle have been proposed. A marked increase of apoptotic cell death in skeletal muscle was found on day 7 post-burn [19] and caspase 3-mediated apoptosis has been implicated in various muscle atrophy models, including burn injury [20, 76, 77]. Our data showed persistent caspase 3-mediated cell apoptosis in gastrocnemius muscle at four weeks post-burn to impend full recovery of muscle mass. 
Prior to our study, the role of caspaseindependent pathway in burn-induced muscle wasting was limited. Caspase-independent mechanisms, such as AIF lead to DNA fragmentation and cell death [25, 78-80]. In this study, we found AIF expression was correlated with an increase of cell death and suggested caspase-independent apoptosis also contributed to burn-induced muscle atrophy.

Furthermore, muscle fibrosis is a progressive irreversible condition indicating impaired muscle healing process and delineated regeneration in response to aging, pathological disorders or trauma [27]. Proper ECM remodeling process is important in muscle regeneration and the recovery of muscle strength [81]. TGF- $\beta$ is a key regulator to drive tissue atrophy and fibrosis $[82,83]$. Ex vivo TGF- $\beta$ treated muscle experiment showed TGF- $\beta$ induced mice muscle atrophy and reduced muscle contractility [84]. TGF- $\beta 1$ is the most abundant isoform of TGF- $\beta$ in mammals. Mice with overexpressing TGF- $\beta 1$ showed myofiber atrophy and collagen accumulation [85]. During muscle damage, excessive TGF- $\beta 1$ impairs ECM remodeling and initiates fibrotic cascade during the recovery phase [86]. Targeting TGF- $\beta 1$ could prevent ECM deposition and improve muscle regeneration in disuse muscle atrophy [87], toxininduced muscle injury [88] as well as dystrophic and age-related muscle wasting [89]. Smad2/3 and CTGF are the downstream mediators associated with TGF- $\beta$-induced fibrosis [90-93]. Therapeutic agents inhibiting pro-fibrotic TGF- $\beta 1 / \mathrm{Smad} 2 / 3$ signaling could prevent renal fibrosis [94], liver fibrosis [95, 96], pulmonary fibrosis [97, 98], and cardiac fibrosis [99-101]. This study showed burn enhanced the expression of TGF- $\beta 1, \mathrm{pSmad} 2 / 3$ and CTGF to stimulate ECM (collagen and fibronectin) accumulation.

Erythropoietin is a multi-function cytokine that can regulate erythropoiesis and protect organs from damage. In an acute heart failure rat model, single $(5,000$ or $10,000 \mathrm{IU} / \mathrm{kg})$ EPO injection decreased caspase-3 expression in renal medulla [102]. Puchulu et al. suggested 3 days of EPO treatment $(1,000 \mathrm{IU} / \mathrm{kg})$ decreased oxidative damage and improved heart function in a rat hypovolemic model. Single-dose EPO $(5,000 \mathrm{IU} / \mathrm{kg})$ protected myocardial apoptosis in rats following carbon monoxide exposure [103]. Overexpressed EPO improved rat heart fibrosis through the PI3K/Akt/TLR4 pathway to suppress the release of mediators such as TGF- $\beta 1$, proinflammatory cytokines, and matrix metalloproteinase [58]. EPO exerts neuroprotective effect in neurodegenerative diseases [104], ischemic brain injury [105, 106], spinal cord injury [107] and motor neuron death post-burn [69]. EPO has also been found to improve muscular dysfunction in various experimental models, possible through increasing autophagy as well as decreasing apoptosis in type 2 diabetic skeletal muscles [65], reducing apoptosis in a crushing injury model [108] and preventing cancer-induced muscle alteration [67]. A C2C12 myotube ischemia model also showed EPO and its derivations could decrease myotube cell death and inflammation [109]. In human trials, weekly EPO injection increased mitochondrial capacity in skeletal muscle [110].

In this study, we found EPO could prevent burn-induced muscle apoptosis through caspasedependent and caspase-independent apoptotic pathways. In addition, EPO inhibited the expression TGF- $\beta 1$ and its downstream signaling to prevent excessive ECM at four weeks post-burn. The possible mechanism of EPO on burn-induced muscle fiber atrophy was summarized in Figure 6. These finding suggests that EPO could potentially be used to preserve functional skeletal muscle tissue and attenuate excessive fibrotic tissue in burn patients.

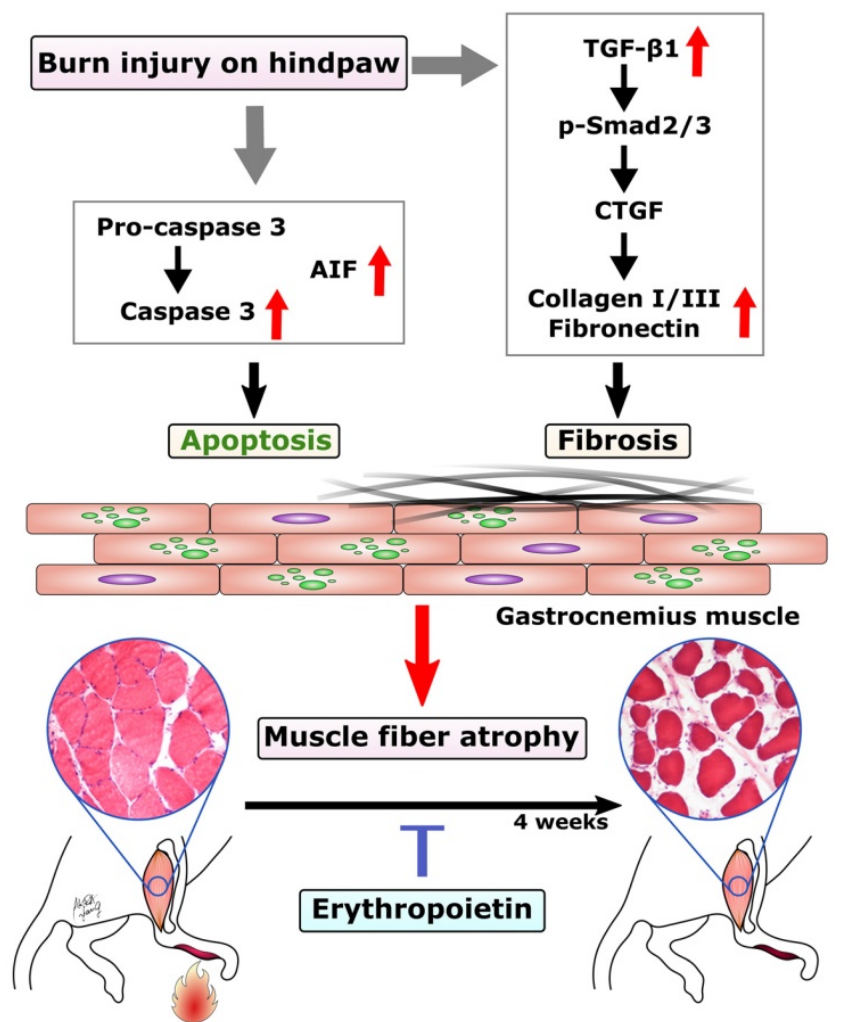

Figure 6. Proposed mechanism of EPO on muscle fiber atrophy following burn. EPO attenuates burn-induced skeletal muscle apoptosis via decreasing the expression of cleaved caspase 3 and AIF at four weeks post-burn. Moreover, EPO modulates burn-induced overexpression of TGF- $\beta 1 / \mathrm{Smad} 2 / 3$ profibrotic pathway and decreases the elevation of CTGF. EPO is a potential therapeutic agent for burn-induced skeletal muscle wasting. Apoptosis-inducing factor (AIF), Transforming growth factor beta 1 (TGF- $\beta 1$ ), phosphorylated Smad2/3 (pSmad2/3), Connective tissue growth factor (CTGF). 


\section{Conclusion}

EPO attenuates burn-induced muscle wasting at 4 weeks post-burn. EPO preserves muscle fiber size and prevents apoptosis after burn through caspasedependent as well as caspase-independent pathway. EPO improves excessive ECM production by suppressing TGF- $\beta 1 /$ Smad signaling and CTGF overexpression following burn.

\section{Abbreviations}

EPO: Erythropoietin; H\&E staining: Hematoxylin \& Eosin staining; TUNEL assay: TdT dUTP nick-end labeling assay; DAPI: 4'6-diamidino2phenylinodole; AIF: Apoptosis-inducing factor; TGF- $\beta 1$ : Transforming growth factor beta 1; CTGF: Connective tissue growth factor.

\section{Acknowledgements}

\section{Funding}

The authors would like to acknowledge the following research grants for funding: Ministry of Science and Technology of Taiwan (MOST107-2314B-037-037, MOST108-2314-B-037-043), Kaohsiung Medical University Hospital (KMUH-106-6R81, KMUH107-7R90), Kaohsiung Municipal Hsiao-Kang Hospital (Kmhk-104-038, Kmhk-106-036), Kaohsiung Medical University Research Foundation (KMUQ108011), Kaohsiung Medical University Research Center Grant (KMU-TC108A02) and Childhood Burn Foundation of the Republic of China.

\section{Author Contributions}

Sheng-Hua Wu: Data curation and analysis, project adminstration, Writing-original draft, I-Cheng Lu: Formal analysis, investigation, Ming-Hong Tai: Methodology, Supervision, Chee-Yin Chai: Software, Supervision, Aij-Lie Kwan: Supervision, Shu-Hung Huang: Conceptuliztion, Data Curation, Writingreview \& editing.

We also gratefully acknowledge Yen-Hsin Kuo and Shin-Ming Yang for technical assistance and preparing figures in this work.

\section{Competing Interests}

The authors have declared that no competing interest exists.

\section{References}

1. Song J, Saeman MR, De Libero J, Wolf SE. Skeletal Muscle Loss is Associated with TNF Mediated Insufficient Skeletal Myogenic Activation After Burn. Shock. 2015; 44: 479-86.

2. Porter C, Tompkins RG, Finnerty CC, Sidossis LS, Suman OE, Herndon DN. The metabolic stress response to burn trauma: current understanding and therapies. Lancet. 2016; 388: 1417-26.

3. Pereira C, Murphy K, Jeschke M, Herndon DN. Post burn muscle wasting and the effects of treatments. The international journal of biochemistry \& cell biology. 2005; 37: 1948-61.
4. Bolton CF. Sepsis and the systemic inflammatory response syndrome: neuromuscular manifestations. Critical care medicine. 1996; 24: 1408-16.

5. Chang DW, DeSanti L, Demling RH. Anticatabolic and anabolic strategies in critical illness: a review of current treatment modalities. Shock. 1998; 10: 155-60.

6. Rinkinen J, Hwang CD, Agarwal S, Oluwatobi E, Peterson J, Loder S, et al. The Systemic Effect of Burn Injury and Trauma on Muscle and Bone Mass and Composition. Plastic and reconstructive surgery. 2015; 136: 612e-23e.

7. Porter C, Hurren NM, Herndon DN, Borsheim E. Whole body and skeletal muscle protein turnover in recovery from burns. International journal of burns and trauma. 2013; 3: 9-17.

8. Hart DW, Wolf SE, Mlcak R, Chinkes DL, Ramzy PI, Obeng MK, et al. Persistence of muscle catabolism after severe burn. Surgery. 2000; 128: 312-9.

9. Jeschke MG, Gauglitz GG, Kulp GA, Finnerty CC, Williams FN, Kraft R, et al. Long-term persistance of the pathophysiologic response to severe burn injury. PloS one. 2011; 6: e21245.

10. St-Pierre DM, Choiniere M, Forget $R$, Garrel DR. Muscle strength in individuals with healed burns. Archives of physical medicine and rehabilitation. 1998; 79: 155-61.

11. Wu X, Wolf SE, Walters TJ. Muscle contractile properties in severely burned rats. Burns : journal of the International Society for Burn Injuries. 2010; 36: 905-11.

12. Ma L, Zhou Y, Khan MAS, Yasuhara S, Martyn JAJ. Burn-Induced Microglia Activation is Associated With Motor Neuron Degeneration and Muscle Wasting in Mice. Shock. 2019; 51: 569-79.

13. Pin F, Bonetto A, Bonewald LF, Klein GL. Molecular Mechanisms Responsible for the Rescue Effects of Pamidronate on Muscle Atrophy in Pediatric Burn Patients. Frontiers in endocrinology. 2019; 10: 543.

14. Clark A, Huebinger RM, Carlson DL, Wolf SE, Song J. Serum Level of Musclin Is Elevated Following Severe Burn. Journal of burn care \& research : official publication of the American Burn Association. 2019; 40: 535-40.

15. Herndon DN, Tompkins RG. Support of the metabolic response to burn injury. Lancet. 2004; 363: 1895-902.

16. Merritt EK, Cross JM, Bamman MM. Inflammatory and protein metabolism signaling responses in human skeletal muscle after burn injury. Journal of burn care \& research : official publication of the American Burn Association. 2012; 33: 291-7.

17. Yu Y, Yang L, Han S, Wu Y, Liu L, Chang Y, et al. MIR-190B Alleviates Cell Autophagy and Burn-Induced Skeletal Muscle Wasting via Modulating PHLPP1/AKT/FOXO3A Signaling Pathway. Shock. 2018.

18. Klein GL. The Role of Bone Secreted Factors in Burn-Induced Muscle Cachexia. Current osteoporosis reports. 2018; 16: 26-31.

19. Lee HY, Kaneki M, Andreas J, Tompkins RG, Martyn JA. Novel mitochondria-targeted antioxidant peptide ameliorates burn-induced apoptosis and endoplasmic reticulum stress in the skeletal muscle of mice. Shock. 2011; 36: 580-5

20. Yasuhara S, Perez ME, Kanakubo E, Yasuhara Y, Shin YS, Kaneki M, et al. Skeletal muscle apoptosis after burns is associated with activation of proapoptotic signals. American journal of physiology Endocrinology and metabolism. 2000; 279: E1114-21.

21. Fry CS, Porter C, Sidossis LS, Nieten C, Reidy PT, Hundeshagen G, et al. Satellite cell activation and apoptosis in skeletal muscle from severely burned children. The Journal of physiology. 2016; 594: 5223-36.

22. Duan H, Chai J, Sheng Z, Yao Y, Yin H, Liang L, et al. Effect of burn injury on apoptosis and expression of apoptosis-related genes/proteins in skeletal muscles of rats. Apoptosis : an international journal on programmed cell death. 2009; 14: 52-65.

23. Sehat A, Huebinger RM, Carlson DL, Zang QS, Wolf SE, Song J. Burn Serum Stimulates Myoblast Cell Death Associated with IL-6-Induced Mitochondrial Fragmentation. Shock. 2017; 48: 236-42.

24. Dupont-Versteegden EE. Apoptosis in skeletal muscle and its relevance to atrophy. World journal of gastroenterology. 2006; 12: 7463-6.

25. Park SY, Lee JH, Kim HY, Yoon KH, Park SK, Chang MS. Differential expression of apoptosis-related factors induces the age-related apoptosis of the gracilis muscle in humans. International journal of molecular medicine. 2014; 33: 1110-6.

26. Marzetti E, Wohlgemuth SE, Lees HA, Chung HY, Giovannini S, Leeuwenburgh C. Age-related activation of mitochondrial caspase-independent apoptotic signaling in rat gastrocnemius muscle. Mechanisms of ageing and development. 2008; 129: 542-9.

27. Cholok D, Lee E, Lisiecki J, Agarwal S, Loder S, Ranganathan K, et al. Traumatic muscle fibrosis: From pathway to prevention. The journal of trauma and acute care surgery. 2017; 82: 174-84.

28. Corrick KL, Stec MJ, Merritt EK, Windham ST, Thomas SJ, Cross JM, et al. Serum from human burn victims impairs myogenesis and protein synthesis in primary myoblasts. Frontiers in physiology. 2015; 6: 184.

29. Kulp GA, Herndon DN, Lee JO, Suman OE, Jeschke MG. Extent and magnitude of catecholamine surge in pediatric burned patients. Shock. 2010; 33: 369-74.

30. Norbury WB, Herndon DN, Branski LK, Chinkes DL, Jeschke MG. Urinary cortisol and catecholamine excretion after burn injury in children. The Journal of clinical endocrinology and metabolism. 2008; 93: 1270-5.

31. Gauglitz GG, Herndon DN, Kulp GA, Meyer WJ, 3rd, Jeschke MG. Abnormal insulin sensitivity persists up to three years in pediatric patients post-burn. The Journal of clinical endocrinology and metabolism. 2009; 94: 1656-64. 
32. Meng XM, Nikolic-Paterson DJ, Lan HY. TGF-beta: the master regulator of fibrosis. Nature reviews Nephrology. 2016; 12: 325-38.

33. Mann CJ, Perdiguero E, Kharraz Y, Aguilar S, Pessina P, Serrano AL, et al. Aberrant repair and fibrosis development in skeletal muscle. Skeletal muscle. 2011; $1: 21$.

34. Taniguti AP, Pertille A, Matsumura CY, Santo Neto H, Marques MJ. Prevention of muscle fibrosis and myonecrosis in $\mathrm{mdx}$ mice by suramin, a TGF-beta1 blocker. Muscle \& nerve. 2011; 43: 82-7.

35. Walton KL, Johnson KE, Harrison CA. Targeting TGF-beta Mediated SMAD Signaling for the Prevention of Fibrosis. Frontiers in pharmacology. 2017; 8: 461.

36. Gabriel VA. Transforming growth factor-beta and angiotensin in fibrosis and burn injuries. Journal of burn care \& research : official publication of the American Burn Association. 2009; 30: 471-81.

37. Penn JW, Grobbelaar AO, Rolfe KJ. The role of the TGF-beta family in wound healing, burns and scarring: a review. International journal of burns and trauma. 2012; 2: 18-28.

38. Castleberry SA, Golberg A, Sharkh MA, Khan S, Almquist BD, Austen WG, Jr., et al. Nanolayered siRNA delivery platforms for local silencing of CTGF reduce cutaneous scar contraction in third-degree burns. Biomaterials. 2016; 95: 22-34.

39. Lin SL, Chen RH, Chen YM, Chiang WC, Lai CF, Wu KD, et al. Pentoxifylline attenuates tubulointerstitial fibrosis by blocking Smad3/4-activated transcription and profibrogenic effects of connective tissue growth factor. Journal of the American Society of Nephrology : JASN. 2005; 16: 2702-13.

40. March JT, Golshirazi G, Cernisova V, Carr H, Leong Y, Lu-Nguyen N, et al. Targeting TGFbeta Signaling to Address Fibrosis Using Antisense Oligonucleotides. Biomedicines. 2018; 6 .

41. Wang D, Wang W, Liang Q, He X, Xia Y, Shen S, et al. DHEA-induced ovarian hyperfibrosis is mediated by TGF-beta signaling pathway. Journal of ovarian research. 2018; 11: 6 .

42. Ogunshola OO, Bogdanova AY. Epo and non-hematopoietic cells: what do we know? Methods in molecular biology. 2013; 982: 13-41.

43. Alnaeeli M, Wang L, Piknova B, Rogers H, Li X, Noguchi CT. Erythropoietin in brain development and beyond. Anatomy research international. 2012; 2012: 953264 .

44. Carraway MS, Suliman HB, Jones WS, Chen CW, Babiker A, Piantadosi CA. Erythropoietin activates mitochondrial biogenesis and couples red cell mass to mitochondrial mass in the heart. Circulation research. 2010; 106: 1722-30.

45. Merelli A, Czornyj L, Lazarowski A. Erythropoietin as a new therapeutic opportunity in brain inflammation and neurodegenerative diseases. The International journal of neuroscience. 2015; 125: 793-7.

46. Nekoui A, Blaise G. Erythropoietin and Nonhematopoietic Effects. The American journal of the medical sciences. 2017; 353: 76-81.

47. Ranjbaran M, Kadkhodaee M, Seifi B, Adelipour M, Azarian B. Erythropoietin attenuates experimental haemorrhagic shock-induced renal damage through an iNOS- dependent mechanism in male Wistar rats. Injury. 2017; 48: 262-9.

48. Lombardero M, Kovacs K, Scheithauer BW. Erythropoietin: a hormone with multiple functions. Pathobiology : journal of immunopathology, molecular and cellular biology. 2011; 78: 41-53.

49. Rundqvist H, Rullman E, Sundberg CJ, Fischer H, Eisleitner K, Stahlberg M, et al. Activation of the erythropoietin receptor in human skeletal muscle. European journal of endocrinology. 2009; 161: 427-34.

50. Andrade DC, Haine L, Toledo C, Diaz HS, Quintanilla RA, Marcus NJ, et al. Ventilatory and Autonomic Regulation in Sleep Apnea Syndrome: A Potential Protective Role for Erythropoietin? Frontiers in physiology. 2018; 9: 1440.

51. Nasri H. Renal Cell Protection of Erythropoietin beyond Correcting The Anemia in Chronic Kidney Disease Patients. Cell journal. 2014; 15: 378-80.

52. Joyeux-Faure M. Cellular protection by erythropoietin: new therapeutic implications? The Journal of pharmacology and experimental therapeutics. 2007; 323: 759-62.

53. Guven Bagla A, Ercan E, Asgun HF, Ickin M, Ercan F, Yavuz O, et al. Experimental acute myocardial infarction in rats: HIF-1alpha, caspase-3, erythropoietin and erythropoietin receptor expression and the cardioprotective effects of two different erythropoietin doses. Acta histochemica. 2013; 115: 658-68.

54. Zhang X, Dong S. Protective Effects of Erythropoietin towards Acute Lung Injuries in Rats with Sepsis and Its Related Mechanisms. Annals of clinical and laboratory science. 2019; 49: 257-64.

55. Zhu M, Wang L, Yang J, Xie K, Zhu M, Liu S, et al. Erythropoietin Ameliorates Lung Injury by Accelerating Pulmonary Endothelium Cell Proliferation via Janus Kinase-Signal Transducer and Activator of Transcription 3 Pathway After Kidney Ischemia and Reperfusion Injury. Transplantation proceedings. 2019; 51: 972-8.

56. Castillo C, Zaror S, Gonzalez M, Hidalgo A, Burgos CF, Cabezas OI, et al. Neuroprotective effect of a new variant of Epo nonhematopoietic against oxidative stress. Redox biology. 2018; 14: 285-94.

57. Zhang XJ, Ma YX, Wen Y, Xu XJ. [Erythropoietin suppresses the expressions of TGF-beta1 and collagen in rat cardiac fibroblasts induced by angiotensin II]. Zhonghua xin xue guan bing za zhi. 2008; 36: 636-40.

58. Liu F, Wen Y, Kang J, Wei C, Wang M, Zheng Z, et al. Regulation of TLR4 expression mediates the attenuating effect of erythropoietin on inflammation and myocardial fibrosis in rat heart. International journal of molecular medicine. 2018; 42: 1436-44
59. Li ZM, Xiao YL, Zhu JX, Geng FY, Guo CJ, Chong ZL, et al. Recombinant human erythropoietin improves functional recovery in patients with severe traumatic brain injury: A randomized, double blind and controlled clinical trial. Clinical neurology and neurosurgery. 2016; 150: 80-3.

60. French CJ, Glassford NJ, Gantner D, Higgins AM, Cooper DJ, Nichol A, et al. Erythropoiesis-stimulating Agents in Critically Ill Trauma Patients: A Systematic Review and Meta-analysis. Annals of surgery. 2017; 265: 54-62.

61. French C. Erythropoietin in Critical Illness and Trauma. Critical care clinics. 2019; 35: 277-87.

62. Lamon S, Russell AP. The role and regulation of erythropoietin (EPO) and its receptor in skeletal muscle: how much do we really know? Frontiers in physiology. 2013; 4: 176.

63. Hoedt A, Christensen B, Nellemann B, Mikkelsen UR, Hansen M, Schjerling P, et al. Satellite cell response to erythropoietin treatment and endurance training in healthy young men. The Journal of physiology. 2016; 594: 727-43.

64. Davenport A, King RF, Ironside JW, Will EJ, Davison AM. The effect of treatment with recombinant human erythropoietin on the histological appearance and glycogen content of skeletal muscle in patients with chronic renal failure treated by regular hospital haemodialysis. Nephron. 1993; 64: 89-94.

65. Pan Y, Yang XH, Guo LL, Gu YH, Qiao QY, Jin HM. Erythropoietin Reduces Insulin Resistance via Regulation of Its Receptor-Mediated Signaling Pathways in $\mathrm{db} / \mathrm{db}$ Mice Skeletal Muscle. International journal of biological sciences. 2017; 13: 1329-40.

66. Ogilvie M, Yu X, Nicolas-Metral V, Pulido SM, Liu C, Ruegg UT, et al. Erythropoietin stimulates proliferation and interferes with differentiation of myoblasts. The Journal of biological chemistry. 2000; 275: 39754-61.

67. Pin F, Busquets S, Toledo M, Camperi A, Lopez-Soriano FJ, Costelli P, et al. Combination of exercise training and erythropoietin prevents cancer-induced muscle alterations. Oncotarget. 2015; 6: 43202-15.

68. Wu SH, Huang SH, Cheng KI, Chai CY, Yeh JL, Wu TC, et al. Third-degree hindpaw burn injury induced apoptosis of lumbar spinal cord ventral horn motor neurons and sciatic nerve and muscle atrophy in rats. BioMed research international. 2015; 2015: 372819.

69. Wu SH, Lu IC, Lee SS, Kwan AL, Chai CY, Huang SH. Erythropoietin attenuates motor neuron programmed cell death in a burn animal model. PloS one. 2018; 13: e0190039.

70. Clavel S, Coldefy AS, Kurkdjian E, Salles J, Margaritis I, Derijard B. Atrophy-related ubiquitin ligases, atrogin-1 and MuRF1 are up-regulated in aged rat Tibialis Anterior muscle. Mechanisms of ageing and development. 2006; 127: 794-801.

71. Gomes MD, Lecker SH, Jagoe RT, Navon A, Goldberg AL. Atrogin-1, a muscle-specific F-box protein highly expressed during muscle atrophy. Proceedings of the National Academy of Sciences of the United States of America. 2001; 98: 14440-5.

72. Porter C, Herndon DN, Sidossis LS, Borsheim E. The impact of severe burns on skeletal muscle mitochondrial function. Burns : journal of the International Society for Burn Injuries. 2013; 39: 1039-47.

73. Ogunbileje JO, Herndon DN, Murton AJ, Porter C. The Role of Mitochondrial Stress in Muscle Wasting Following Severe Burn Trauma. Journal of burn care \& research : official publication of the American Burn Association. 2018; 39: 100-8.

74. Porter C, Herndon DN, Borsheim E, Bhattarai N, Chao T, Reidy PT, et al. Long-Term Skeletal Muscle Mitochondrial Dysfunction is Associated with Hypermetabolism in Severely Burned Children. Journal of burn care \& research : official publication of the American Burn Association. 2016; 37: 53-63.

75. Nakazawa H, Chang K, Shinozaki S, Yasukawa T, Ishimaru K, Yasuhara S, et al. iNOS as a Driver of Inflammation and Apoptosis in Mouse Skeletal Muscle after Burn Injury: Possible Involvement of Sirt1 S-Nitrosylation-Mediated Acetylation of p65 NF-kappaB and p53. PloS one. 2017; 12: e0170391.

76. Siu PM, Alway SE. Mitochondria-associated apoptotic signalling in denervated rat skeletal muscle. The Journal of physiology. 2005; 565: 309-23.

77. Leeuwenburgh C, Gurley CM, Strotman BA, Dupont-Versteegden EE. Age-related differences in apoptosis with disuse atrophy in soleus muscle. American journal of physiology Regulatory, integrative and comparative physiology. 2005; 288: R1288-96.

78. Cande C, Cohen I, Daugas E, Ravagnan L, Larochette N, Zamzami N, et al. Apoptosis-inducing factor (AIF): a novel caspase-independent death effector released from mitochondria. Biochimie. 2002; 84: 215-22.

79. Li LY, Luo X, Wang X. Endonuclease G is an apoptotic DNase when released from mitochondria. Nature. 2001; 412: 95-9.

80. Daugas E, Nochy D, Ravagnan L, Loeffler M, Susin SA, Zamzami N, et al. Apoptosis-inducing factor (AIF): a ubiquitous mitochondrial oxidoreductase involved in apoptosis. FEBS letters. 2000; 476: 118-23.

81. Hyldahl RD, Nelson B, Xin L, Welling T, Groscost L, Hubal MJ, et al. Extracellular matrix remodeling and its contribution to protective adaptation following lengthening contractions in human muscle. FASEB journal : official publication of the Federation of American Societies for Experimental Biology. 2015; 29: 2894-904.

82. Rosenbloom J, Mendoza FA, Jimenez SA. Strategies for anti-fibrotic therapies. Biochimica et biophysica acta. 2013; 1832: 1088-103.

83. Borthwick LA, Wynn TA, Fisher AJ. Cytokine mediated tissue fibrosis. Biochimica et biophysica acta. 2013; 1832: 1049-60. 
84. Mendias CL, Gumucio JP, Davis ME, Bromley CW, Davis CS, Brooks SV. Transforming growth factor-beta induces skeletal muscle atrophy and fibrosis through the induction of atrogin-1 and scleraxis. Muscle \& nerve. 2012; 45: 55-9.

85. Narola J, Pandey SN, Glick A, Chen YW. Conditional expression of TGF-beta1 in skeletal muscles causes endomysial fibrosis and myofibers atrophy. PloS one. 2013; 8: e79356.

86. Kim J, Lee J. Role of transforming growth factor-beta in muscle damage and regeneration: focused on eccentric muscle contraction. Journal of exercise rehabilitation. 2017; 13: 621-6.

87. Burks TN, Andres-Mateos E, Marx R, Mejias R, Van Erp C, Simmers JL, et al. Losartan restores skeletal muscle remodeling and protects against disuse atrophy in sarcopenia. Science translational medicine. 2011; 3: 82ra37.

88. Hwang OK, Park JK, Lee EJ, Lee EM, Kim AY, Jeong KS. Therapeutic Effect of Losartan, an Angiotensin II Type 1 Receptor Antagonist, on CCl(4)-Induced Skeletal Muscle Injury. International journal of molecular sciences. 2016; 17: 227.

89. Zhang P, He J, Wang F, Gong J, Wang L, Wu Q, et al. Hemojuvelin is a novel suppressor for Duchenne muscular dystrophy and age-related muscle wasting. Journal of cachexia, sarcopenia and muscle. 2019.

90. Tsai CC, Wu SB, Kau HC, Wei YH. Essential role of connective tissue growth factor (CTGF) in transforming growth factor-beta1 (TGF-beta1)-induced myofibroblast transdifferentiation from Graves' orbital fibroblasts. Scientific reports. 2018; 8: 7276

91. Nagaraja T, Chen L, Balasubramanian A, Groopman JE, Ghoshal K, Jacob ST, et al. Activation of the connective tissue growth factor (CTGF)-transforming growth factor beta 1 (TGF-beta 1) axis in hepatitis C virus-expressing hepatocytes. PloS one. 2012; 7: e46526.

92. Khalil H, Kanisicak O, Prasad V, Correll RN, Fu X, Schips T, et al. Fibroblast-specific TGF-beta-Smad2/3 signaling underlies cardiac fibrosis. The Journal of clinical investigation. 2017; 127: 3770-83

93. Ren M, Wang B, Zhang J, Liu P, Lv Y, Liu G, et al. Smad2 and Smad3 as mediators of the response of adventitial fibroblasts induced by transforming growth factor beta1. Molecular medicine reports. 2011; 4: 561-7.

94. Meng XM, Tang PM, Li J, Lan HY. TGF-beta/Smad signaling in renal fibrosis. Frontiers in physiology. 2015; 6: 82.

95. Yang HY, Kim KS, Lee YH, Park JH, Kim JH, Lee SY, et al. Dendropanax morbifera Ameliorates Thioacetamide-Induced Hepatic Fibrosis via TGF-beta1/Smads Pathways. International journal of biological sciences. 2019; 15: 800-11.

96. Lim BJ, Lee WK, Lee HW, Lee KS, Kim JK, Chang HY, et al. Selective deletion of hepatocyte platelet-derived growth factor receptor alpha and development of liver fibrosis in mice. Cell communication and signaling : CCS. 2018; 16: 93.

97. Liu G, Wang Y, Yang L, Zou B, Gao S, Song Z, et al. Tetraspanin 1 as a mediator of fibrosis inhibits EMT process and $S \operatorname{mad} 2 / 3$ and beta-catenin pathway in human pulmonary fibrosis. Journal of cellular and molecular medicine. 2019; 23: 3583-96.

98. Jia $\mathrm{L}$, Sun $\mathrm{P}$, Gao $\mathrm{H}$, Shen $\mathrm{J}$, Gao $\mathrm{Y}$, Meng $\mathrm{C}$, et al Mangiferin attenuates bleomycin-induced pulmonary fibrosis in mice through inhibiting TLR4/p65 and TGF-beta1/Smad2/3 pathway. The Journal of pharmacy and pharmacology. 2019; 71: 1017-28.

99. Yuan $\mathrm{Q}$ Cao S, Dong $\mathrm{Q}$ Wang $\mathrm{Z}, \mathrm{Xu}$ Y, Han $\mathrm{Q}$ et al. ALDH2 Activation Inhibited Cardiac Fibroblast-to-Myofibroblast Transformation Via the TGF-beta1/Smad Signaling Pathway. Journal of cardiovascular pharmacology. 2019; 73: 248-56.

100. Chen RR, Fan XH, Chen G, Zeng GW, Xue YG, Liu XT, et al. Irisin attenuates angiotensin II-induced cardiac fibrosis via Nrf2 mediated inhibition of ROS/ TGFbeta1/Smad2/3 signaling axis. Chemico-biological interactions. 2019; 302: 11-21.

101. Vilahur G, Casani L, Pena E, Crespo J, Juan-Babot O, Ben-Aicha S, et al. Silybum marianum provides cardioprotection and limits adverse remodeling post-myocardial infarction by mitigating oxidative stress and reactive fibrosis. International journal of cardiology. 2018; 270: 28-35.

102. Guven Bagla A, Ickin Gulen M, Ercan F, Asgun F, Ercan E, Bakar C. Changes in kidney tissue and effects of erythropoietin after acute heart failure. Biotechnic \& histochemistry : official publication of the Biological Stain Commission. 2018; 93: 340-53

103. Rezaee MA, Mohammadpour AH, Imenshahidi M, Mahmoudi M, Sankian M, Tsarouhas K, et al. Protective effect of erythropoietin on myocardial apoptosis in rats exposed to carbon monoxide. Life sciences. 2016; 148: 118-24.

104. Hernandez CC, Burgos CF, Gajardo AH, Silva-Grecchi T, Gavilan J, Toledo JR, et al. Neuroprotective effects of erythropoietin on neurodegenerative and ischemic brain diseases: the role of erythropoietin receptor. Neural regeneration research. 2017; 12: 1381-9.

105. Juul SE, Comstock BA, Heagerty PJ, Mayock DE, Goodman AM, Hauge S, et al. High-Dose Erythropoietin for Asphyxia and Encephalopathy (HEAL): A Randomized Controlled Trial - Background, Aims, and Study Protocol. Neonatology. 2018; 113: 331-8.

106. Fernando G, Yamila R, Cesar GJ, Ramon R Neuroprotective Effects of neuroEPO Using an In Vitro Model of Stroke. Behavioral sciences. 2018; 8.

107. Yamanaka K, Eldeiry M, Aftab M, Ryan TJ, Mares J, Meng X, et al. Synergistic Reduction of Apoptosis With Diazoxide and Erythropoietin in Spinal Cord Ischemic Injury. The Annals of thoracic surgery. 2018; 106: 1751-8.

108. Rotter R, Menshykova M, Winkler T, Matziolis G, Stratos I, Schoen M, et al. Erythropoietin improves functional and histological recovery of traumatized skeletal muscle tissue. Journal of orthopaedic research : official publication of the Orthopaedic Research Society. 2008; 26: 1618-26.

109. Joshi D, Abraham D, Shiwen X, Baker D, Tsui J. Potential role of erythropoietin receptors and ligands in attenuating apoptosis and inflammation in critical limb ischemia. Journal of vascular surgery. 2014; 60: 191-201, e1-2.

110. Plenge U, Belhage B, Guadalupe-Grau A, Andersen PR, Lundby C, Dela F, et al. Erythropoietin treatment enhances muscle mitochondrial capacity in humans. Frontiers in physiology. 2012; 3: 50. 